\title{
Lower Parental Numeracy is Associated with Children Being Under- and Overweight
}

\begin{abstract}
Background: In adults, lower numeracy is associated with poorer nutrition label comprehension and higher BMI. It remains unclear whether parental numeracy also impacts children's body weight. Purpose: We examined the relationship between parental numeracy and children's BMI $z$-scores and analyzed whether weight-related numerical information processing skills — specifically, portion-size estimation skills, comprehension of nutrition labels, and comprehension of growth charts—-mediated that relationship. Design and
\end{abstract} Methods: Numeracy, portion-size estimation skills, comprehension of nutrition labels, and comprehension of growth charts were assessed in face-to-face interviews with 320 parents of children aged 6 to 12 years in Germany. Parent and child body weight were measured; parents reported both their own height and that of their children. Results: Lower parental numeracy was significantly associated with having a child who was either underweight $(\beta=0.126, P=$ $.048)$ or overweight $(\beta=-0.299, P<.001)$. Lower parental numeracy was also associated with poorer portion-size estimation skills $(r=-0.08, P=.023)$ and inferior comprehension of growth charts $(r=0.33, P<.001)$ and nutrition labels $(r=0.26, P<.001)$. However, these weight-related numerical information processing skills did not mediate the association between parental numeracy and children's BMI. Conclusion: This study is the first to find lower parental numeracy to be a risk factor for children being either over- or underweight. However, portion-size estimation skills, comprehension of nutrition labels, and comprehension of growth charts did not mediate the association between parental numeracy and children's BMI. The present findings thus winnow down the set of mechanisms potentially underlying this association. Parental numeracy is an as yet largely overlooked factor that can be targeted when developing interventions to prevent and treat malnutrition and to achieve and maintain a healthy body weight in children. 
Keywords: Germany, numeracy, body mass index, children, nutrition labeling, portion size, growth charts 


\section{Introduction}

Numeracy is the ability to understand and use numbers in daily life. It is known to play a role in people's health decisions and to affect health outcomes (Lipkus \& Peters, 2009). For example, numeracy has been shown to be important for understanding medical instructions (Williams et al., 1995), health risks (Gigerenzer, Gaissmaier, Kurz-Milcke, Schwartz, \& Woloshin, 2007), and health information expressed in probabilities, graphs, or tables (Peters, Hibbard, Slovic, \& Dieckmann, 2007; Sheridan, Pignone, \& Lewis, 2003). These findings may also be relevant in the context of nutrition and healthy body weight. Thus far, however, only a few studies have investigated the role of numeracy in weight outcomes and weightrelated numerical information processing. Their findings suggest that lower numeracy is associated with poorer comprehension of nutrition labels (Rothman et al., 2006) and inferior portion-size estimation skills (Huizinga et al., 2009). Further, lower numeracy skills have been associated with a higher body mass index (BMI) in adult primary care patients (Huizinga, Beech, Cavanaugh, Elasy, \& Rothman, 2008). The effects of numeracy on weightrelated information processing or BMI persist when other important factors, such as education or socioeconomic status, are controlled (Huizinga, Beech et al., 2008; Rothman et al., 2006).

\section{Research Goals}

This study examines three issues that have not been addressed in previous research:

First, we examine the extent to which lower parental numeracy may represent a risk factor for children being over- or underweight. This question is important because a growing consensus exists among experts that parents, as "nutritional gatekeepers" (Wansink, 2006, p. 162), play a key role in the nutritional health of their dependents. Consequently, interventions targeting a child's obesity do not necessarily need to involve the child as an active agent to be effectiveit suffices to target the parents (Golan \& Crow, 2004). We therefore examine how the numerical skills of parents relate to the weight status of their children. 
Second, malnutrition can lead to individuals being either underweight or overweight. Both states are associated with negative health outcomes. Underweight children have an increased risk of osteoporosis, bone disease, and reduced fertility in adulthood. They also report a negative body image more often than children with normal weight (Luder \& Alton, 2005). Childhood obesity is associated with serious health conditions such as diabetes or asthma and predicts adult obesity (Daniels, 2009; Guo \& Chumlea, 1999; Weiss \& Caprio, 2005). Importantly, previous studies investigating the relationship of adults' numerical skills and BMI have included few, if any, underweight participants. It therefore remains unclear whether the link between numeracy and deviations from recommended BMI levels applies to both over- and underweight. This issue is particularly relevant for children, who are more likely than other subsections of the population to be underweight (Kurth \& Schaffrath Rosario, 2007; Mensink et al., 2013). Examining children therefore allows us to study how parental numeracy is associated with children being either over- or underweight.

Third, the mechanisms potentially underlying the link between numeracy and BMI are unexplored. This study examines three numerical information processes that may mediate the association between parents' ability to understand and use numbers and their children's BMI (see Fig. 1): (a) comprehension of nutrition labels (important for judging the nutritional value and healthiness of food; Temple \& Fraser, 2014), (b) portion-size estimation skills (essential for following dietary recommendations; Huizinga, Pont, et al., 2008; Pourshahidi, Kerr, McCaffrey, \& Livingstone, 2014), and (c) comprehension of growth charts (which provide information about a child's weight status and serve, in turn, as a basis for decisions about nutrition and portion sizes; Ben-Joseph, Dowshen, \& Izenberg, 2009). All three processes require, among other skills, the ability to understand and use numbers. However, it is likely that not all parents are able to enlist such numerical skills. For instance, in one study with a nationally representative sample of U.S. parents, $77 \%$ misinterpreted information contained in 
growth charts (Ben-Joseph et al., 2009). This misinterpretation may originate, at least partly, in inadequate numerical skills (Peters, Meilleur, \& Tompkins, 2013).

\section{Hypotheses}

We hypothesize that (1) lower parental numeracy will co-occur with their children being under- or overweight; and that (2) weight-related numerical information processing skillsspecifically, portion-size estimation skills, comprehension of nutrition labels, and comprehension of growth charts - will mediate the relationship between parental numeracy skills and their children's BMI.

\section{Methods}

\section{Participants}

Parent-child dyads were recruited and interviewed by the Gesellschaft fuer Konsumforschung (GfK), one of the largest commercial market research institutes in Europe. Interviews were conducted between November and December 2014. The sample was representative of the German population with respect to gender, age, region, size of place of residence, size of household, and profession of head of household. Parents were included if they identified themselves as nutritional gatekeepers and had one or more children aged between 6 and 12 years who were at home during the face-to-face interview. When more than one child was at home, the child with the birthday closest to the day of the interview was selected. Parents were classified as nutritional gatekeepers if they identified themselves as "the person in the household who has the strongest influence on what and how much [the] child eats" and who is "responsible for planning and preparing [the] family's food" (Wansink, 2006, p. 162). The total sample consisted of 326 parent-child dyads. Five dyads were excluded due to omissions or measurement errors in height or weight data and one dyad was excluded due to an error in data entry, resulting in a final data set of 320 dyads (see Table 1, which also compares the 
demographics of the study sample with that of the overall German population). The Ethics Committee of the Max Planck Institute for Human Development, Berlin, approved this study.

\section{Materials and Procedure}

Computer-assisted face-to-face interviews were conducted, with the interviewer being present while the parent completed computerized tasks and questionnaires. The body weight of parent and child was measured with a scale after the interview; parents reported their own height and that of their child. Parents' BMI was calculated from height and weight measures; children's measures were transformed into BMI $z$-scores (z-BMI) based on the distributions of a German reference population (Neuhauser, Schienkiewitz, Schaffrath Rosario, Dortschy, \& Kurth, 2013). This procedure permits comparisons across children of different ages and across girls and boys (Wang \& Chen, 2012). Specifically, the $z$-BMI indicates in what direction (above/positive or below/negative) and by how much a child's BMI deviates from the reference mean, defined as normal weight. For instance, a $z$-BMI score of -2.0 indicates that a child's $z$-BMI is 2.0 standard deviations below the reference mean (and a $z$-BMI score of 2.0 indicates that a child's $z$-BMI is 2.0 standard deviation above the reference mean).

Additionally to the $z$-BMI score, we computed the absolute $z$-BMI score, which indicates how much the child's $z$-BMI deviates from the reference mean without taking into account the direction of the deviation (above/positive or below/negative). For instance, an absolute $z$-BMI score of 2.0 indicates that a child's $z$-BMI is 2.0 standard deviations away from reference mean, without indicating the direction of the deviation (above or below the reference mean). Children were then classified as underweight $\left(\mathrm{BMI}<10^{\text {th }}\right.$ percentile; $z$-BMI $\left.<-1.28\right)$, normal weight $\left(\right.$ BMI $10^{\text {th }}-90^{\text {th }}$ percentile; $z-$ BMI: $\left.-1.28-1.28\right)$, overweight $\left(\right.$ BMI $>90^{\text {th }}$ percentile; $z-$ $\mathrm{BMI}>1.28)$, or obese $\left(\mathrm{BMI}>97^{\text {th }}\right.$ percentile; $\left.z-\mathrm{BMI}>1.88\right)$ on the basis of recommended guidelines (The German Working Group of Obesity in Childhood and Adolescence [AGA], 2011; Neuhauser et al., 2013). 
Parental numeracy was assessed using the eight-item scale by Weller and colleagues (2012).

This scale measures participants' understanding of numerical information (e.g., "If the chance of getting a disease is 20 out of 100, this would be the same as having a _ \% chance of getting the disease"; "Imagine that we roll a fair, six-sided die 1,000 times. Out of 1,000 rolls, how many times do you think the die would come up as an even number?"). Numeracy was scored as the number of correct responses out of eight and was used as a continuous measure in the analyses. This abbreviated numeracy scale was developed and intended for use in large, diverse samples; Cronbach's $\alpha=.71$ (Weller et al., 2012).

Physical activity of the child was measured by asking the parent to estimate the number of days per week on which the child was physically active for a total of at least 60 minutes.

Comprehension of nutrition labels was measured using questions from the Nutrition Label Survey (NLS; Rothman et al., 2006). In the NLS, participants are shown nutrition labels of typical food products and asked about their nutritional value. For example, they are shown the nutrition label for a bottle of Coca-Cola and asked, "You drink this whole bottle of CocaCola. How many grams of total carbohydrates does this contain?” (see Supplementary Materials). After testing the NLS items in a pilot study, we selected five items from the original 24-item instrument based on their inter-item correlations in the pilot study, their loading on the common factor, and their varying item difficulty (low, medium, and high difficulty). Nutrition label comprehension was scored as the total number of correct responses. Internal consistency and reliability of the five-item questionnaire was good, Cronbach's $\alpha=.74$.

Comprehension of growth charts was measured using seven items from the growth chart survey developed by the Nemours Center for Children's Health Media (KidsHealth) and Cogent Research (www.kidshealth.org/misc/surveys/GrowthChartSurvey.pdf). Parents were presented with a growth chart that is routinely used by German health care providers to, for 
example, monitor children's growth during pediatric check-ups. They then indicated their familiarity with the chart (e.g., "Prior to this survey, had you ever seen this before?") and understanding of the chart (e.g., "Please look at the chart above, and locate the point showing the child's measurement. Based on this point, how old is this child?"). Growth chart comprehension was scored as the total number of correct responses. A pilot study revealed good reliability of the seven-item growth charts scale (Cronbach's $\alpha=.73$ ).

Portion-size estimation skills were assessed using five sets of food pictures portraying typical foods for children (e.g., cornflakes for breakfast or lentil stew for lunch). Each set contained 15 pictures depicting varying amounts of the same food. The first picture showed an empty plate with a fork or spoon as a reference for magnitude, followed by a picture with a very small amount of the respective food. The remaining 13 photos presented increasing amounts of the food, with standardized increases in gram amounts corresponding to approximately one tablespoon (see Supplementary Materials for an example). The pictures were presented one at a time on a computer screen. Parents were asked: "The recommended amount for children aged $[\mathrm{XX}]$ years is $[\mathrm{YYY}]$ grams. Among the following pictures, please choose the one that shows the recommended amount." They were shown how to scroll through the pictures and instructed to click the "recommended amount button" to select the relevant picture. We scored the portion size estimates by calculating the absolute deviation between the chosen and the recommended amount so that lower scores meant better performance. Menus and food amounts came from the Optimized Mixed Diet (OMD; Alexy, Clausen, \& Kersting, 2008). The Optimized Mixed Diet adheres to the WHO standards for Food-Based Dietary Guidelines and takes into account meal patterns and children's preferences. The predictive validity and reliability of the picture sets were tested in a pilot study, in which parents estimated portion sizes from real food and from pictures. The results of the pilot study revealed good predictive validity $(r=.60-.80)$ and high re-test reliability $(r>.80)$. 
The ethics committee of the Max Planck Institute for Human Development, Berlin, Germany, approved the study. All participants gave their informed consent prior to the study.

\section{Statistical Analyses}

One missing value was observed for education level (see Table 1) and was deleted list-wise. To examine the first hypothesis, according to which lower parental numeracy co-occurs with children being under- or overweight, we conducted three multiple linear regression analyses of the child's $z$-BMI: (1) To examine the association between lower parental numeracy and children's underweight, we included only children with z-BMI scores lower than or equal to the recommended $z$-BMI, using their $z$-BMI score as the dependent variable; (2) to examine the association between lower parental numeracy and children's overweight, we included only children with $z$-BMI scores equal to or higher than the recommended $z$-BMI, using their $z-$ BMI score as the dependent variable, and (3) to capture both associations in one analysis, we included all children, using their absolute $z$-BMI scores as the dependent variable. All three regressions included parental numeracy as the independent variable and parents' education level and BMI as well as child's age, gender, and physical activity as covariates. To examine the second hypothesis, according to which weight-related numerical information processing skills mediate the relationship between numeracy and absolute $z$-BMI, we conducted an adjusted multiple mediation analysis. Specifically, we separately tested the mediating role of nutrition label comprehension, growth chart comprehension, and portionsize estimation skills. The bootstrapping sampling method (with 5000 re-samples) was used to assess the significance of a mediation effect. All statistical analyses were performed using SPSS v.22.0 (IBM Corp. Armonk, NY, USA) and R software (R Development Core Team, 2011). For the mediation analysis, we used the SPSS PROCESS script by Hayes (2012).

\section{Results}




\section{Descriptive Sample Characteristics}

The sociodemographic characteristics of the 320 nutritional gatekeepers in this study were generally comparable to those of a representative German sample of household managers (defined as the person in the household responsible for household duties, including food purchases and preparation) from Media Perspective Data, 2014 (ARD-Werbegesellschaften, 2014) with regard to gender, age, size of household, and size of place of residence (Table 1). However, a higher proportion of participants in our sample had a lower level of formal education than in the representative sample. Consequently, we controlled for education level in all analyses. Moreover, a larger proportion of children in our sample were underweight or obese than in the same age group in the representative sample.

\section{Link between Parents' Numeracy and Children's BMI}

Figure 2 plots parental numeracy as a function of children's BMI categories. A linear multiple regression analysis including only children with $z$-BMI scores lower than or equal to the recommended $z$-BMI as the outcome variable revealed a positive association between the child's $z$-BMI and parental numeracy, indicating that lower parental numeracy predicts lower $z$-BMI in these children $(\beta=0.126, P=.048)$. A linear multiple regression analysis including only children with $z$-BMI scores equal to or higher than the recommended $z$-BMI as the outcome variable revealed a negative association between the child's $z$-BMI and parental numeracy, indicating that lower parental numeracy predicts higher $z$-BMI in these children $(\beta$ $=-0.299, P<.001)$. Including all children and using the absolute $z$-BMI score as the outcome variable, we found a negative association between the child's absolute $z$-BMI and parental numeracy, indicating that lower numeracy predicts greater deviation from normal weight $(\beta=$ $-0.369, P<.001)$. With respect to the control variables, the child's $z$-BMI was only significantly associated with the child's age (in the sample with lower than or equal to recommended $z$-BMI: $\beta=0.151, P=.017$; higher than or equal to recommended $z$-BMI: $\beta=$ 
$-0.114, P=.039$, absolute $z$-BMI: $\beta=-0.175, P=.001$ ) and parents' education level (in the sample with higher than or equal to recommended $z$-BMI: $\beta=-0.114, P=.03$; see Table 2 for correlations between all measures used in the study).

\section{Mediating Role of Weight-Related Numerical Information Processing}

Table 3 summarizes results of the mediation analysis. There were significant associations between higher numeracy and better performance on the three weight-related numerical information processing skills: comprehension of nutrition labels; comprehension of growth charts; and portion-size estimation skills. However, the indirect effects of numeracy on absolute $z$-BMI score via the three weight-related numerical information processes did not reach significance. Although all relationships observed were in the predicted direction, none of the variables mediated the link between numeracy and the absolute $z$-BMI scores. This non-significant mediation can be partly explained by the lack of associations between the candidate mediators and child's absolute $z$-BMI (see Table 2).

\section{Discussion}

To the best of our knowledge, this investigation is the first to focus on the link between parents' numeracy and their children's BMI levels. Furthermore, we tested cognitive mechanisms potentially underlying such a link. We found support for the hypothesized link between lower parental numeracy and a larger absolute deviation of the child's $z$-BMI from the recommended z-BMI: Importantly, lower parental numeracy scores were associated with deviations in both directions, that is, with both under- and overweight in children. Furthermore, higher numeracy was associated with better comprehension of nutrition labels, better comprehension of growth charts, and better portion-size estimation skills. However, we found no support for the hypothesis that the link between parental numeracy and children's BMI was mediated by these weight-related numerical information processing skills. 
The present findings complement previous results on the role of parental numeracy and children's health. For instance, above and beyond the effects of education or socioeconomic status, lower parental numeracy has been found to be associated with insufficient glycemic control in children with diabetes (Pulgaron et al., 2014), with inappropriate usage of cough medicine for children (Lokker et al., 2009), and with asthma morbidity in children with asthma (Rosas-Salazar et al., 2013). Furthermore, our findings extend the work of Huizinga and colleagues (2008), who reported a link between numeracy and BMI in adults.

Importantly, the relation between lower numeracy and underweight had not previously been investigated. Our findings show that parental numeracy also seems to be involved in children's underweight. This is an important observation because being under- or overweight as a child has been found to have detrimental effects on health and development (Daniels, 2009; Luder \& Alton, 2005). Our findings highlight the potentially important role that parental numeracy plays for their children's healthy body weight.

Another goal of our study was to examine cognitive mechanisms potentially underlying the hypothesized link between numeracy and BMI. Contrary to our hypothesis, weight-related numerical information processing skills did not mediate the link. This finding can be at least partly explained by the lack of associations between parental weight-related numerical information processing skills and children's BMI. Yet we did find an association between higher parental numeracy and better portion-size estimation skills, better comprehension of nutrition labels, and better comprehension of growth charts. This result underlines the importance of numerical skills for processing weight-related numerical information. Possible negative health outcomes of poor weight-related numerical information processing skills include macro-malnutrition (inappropriate level of energy, protein, fat) and micromalnutrition (inappropriate level of vitamins, minerals). Neither macro- nor micromalnutrition will necessarily result in children being over- or underweight, but they are 
associated with various long- and short-term health risks (Chandra, 2002; Liu, Raine, Venables, \& Mendick, 2004; Tulchinsky, 2010).

We can think of several possible explanations for the finding that weight-related numerical information processing skills did not mediate the association between parental numeracy and children's BMI. One is that we investigated processing skills that are assumed to play a role in children's dietary behavior. For example, if parents misinterpret nutrition labels on fitness drinks, they may underestimate the amount of sugar contained and allow their children to consume more than recommended amount. However, parental numeracy could also affect children's BMI through cognitive processes that are not directly related to dietary behavior. For example, it may take effect by parents competently monitoring the time their children spend in sedentary (e.g., watching TV) relative to physical activities. Alternatively, parents' numeracy (or lack thereof) may increase (or reduce) their perception of the risk involved in their child being overweight or underweight and its long-term consequences (e.g., a quadrupled risk of adult hypertension in obese children; Watson et al., 2013). Still another reason is that numeracy goes beyond comprehension (Peters, 2012, p. 31); higher numeracy coincides with, for instance, lower sensitivity to framing effects and lower susceptibility to non-numerical information (Peters, 2012). In fact, the processing of non-numerical information may be particularly relevant in highly engineered choice architectures such as supermarkets and fast food restaurants, in which a myriad of non-numerical drivers such as a food's taste and images are designed to stimulate food consumption (Cohen \& Babey, 2012). In summary, our investigation suggests that parental numeracy—an important cognitive skill in a world rife with numerical information — predicts children's weight status. Specifically, low parental numeracy appears to be a risk factor for children's under- and overweight. However, this risk can evidently not be attributed to high-numeracy parents being better able to processes numerical weight-related information. We discussed several possible reasons for 
this finding. Our focus in this study was on numeracy and the ability to process weight-related numerical information as potentially important skills for parents who are their children's food choice architects. Yet many other parental behaviors and cognitions shape children's dietary behavior and BMI, including parents' motivation, attitudes, control beliefs, and planning behavior (Baranowski, Cullen, Nicklas, Thompson, \& Baranowski, 2003). Some of them could also play a role in the association between parental numeracy and children's BMI. Consider, for instance, motivation. A parent struggling with low numeracy may underestimate the risks associated with childhood obesity and thus be less motivated to monitor and modify the child's behavior. Further research is required to winnow down the set of potential factors mediating the link between numeracy and BMI.

\section{Strengths and Limitations}

Our study is the first to show that parental numeracy relates to deviations (in both directions) from normal weight in their children. It does so by investigating a community-based sample that, in many important respects, reflects the German population at large. Another strength is that we tested three cognitive factors potentially mediating the association between parental numeracy and children's BMI. Identifying the mechanisms underlying this relationship will be an important step toward developing effective interventions promoting healthy body weight in children.

Our study also has limitations. First, the data collected are cross-sectional; consequently, we could not explore temporal dynamics in the relationship between parental numeracy and children's BMI, and no causal inferences can be drawn. Second, as in previous studies, we found parental education and numeracy to be correlated, suggesting that education could drive the effects found. Specifically, we found that lower parental numeracy scores were associated with a lower education level. However, as we controlled for education level in all analyses, 
our results reflect the effects of numeracy on children's BMI above and beyond the effects of education. Therefore, the results suggest that numeracy could in fact be one of the explanations for why lower education level is associated with poorer health. Third, our results were not entirely representative of German households. In particular, the nutritional gatekeepers in the present sample had a lower education level than did heads of households in the German population at large. Accordingly, it is possible that numeracy scores in the present sample are lower than in the German population at large. To the best of our knowledge, no previous study with a nationally representative sample has used the eight-item Weller scale. However, four items from the Weller scale stem from the Lipkus, Samsa, and Rimer (2001) numeracy scale. This scale has been tested in a probabilistic, national sample representative for the German population (see Galesic \& Garcia-Retamero, 2010). The percentage of participants correctly answering these four items was lower in our sample than in the representative sample (depending on the item, 40-60\% participants in our study vs. $68-88 \%$ in the representative sample). Fourth, the proportion of children in our study sample who were underweight or obese was larger than in the same age group in the reference population. This added variability permitted us to examine a previously neglected group at risk, namely, underweight children. We have thus been able to conclude that parental numeracy may also be a key factor in children being underweight. Fifth, because of the number of constructs assessed, we used shortened scales to measure comprehension of nutrition labels and growth charts. This may have limited our ability to detect meaningful relations. However, a pilot study showed that the short scales had satisfactory psychometric properties. Sixth, we cannot exclude the possibility that spatial awareness may contribute to portion size estimation or growth chart use. We are not aware of any study examining the role of spatial awareness in either context. Further research is warranted here. Finally, parents reported their child's height, which may have influenced results. Importantly, body weight was measured directly, and previous research has shown that parents only slightly overestimate body height; the bias 
between self-reported and measured BMI stems mainly from parents underestimating children's body weight (Huybrechts et al., 2011; Nyholm et al., 2007).

\section{Practical Implications}

Our results have potentially important practical implications: In numerous OECD member countries, including Germany and the US, large segments of the population have relatively poor numeracy skills (OECD, 2013). Our study shows that parental numeracy, that is, parental ability to comprehend numbers across domains, is a significant predictor of children's BMI as well as of the parent's nutrition label comprehension, growth chart comprehension, and portion size estimation. These results imply that parents with lower numeracy will have more difficulty estimating how much their children eat, determining whether their child eats according to nutritional recommendations, and monitoring their child's healthy growth over time. The role of parental numeracy should be taken into account when developing strategies to prevent and treat childhood malnutrition and weight-related issues (being obese or seriously underweight). Such strategies could include easily understandable and transparent communication of children's weight status and dietary recommendations by health care providers. Visual aids and colored information labels could help parents with lower numeracy skills to understand important crucial health- and weightrelated information. For example, traffic light coding could be applied to growth charts, with green and red components indicating that the child's weight falls within or outside of a healthy range. Importantly, however, this and other communications would need to be tested carefully with the target audience of less numerate parents. Another important component of policy interventions may be to consider the role of numerical skills in understanding educational materials about healthy weight management. For example, it may be helpful to use non-numerical descriptions or color coding, or simple tools that help to determine proper portion sizes. Finally, it seems important to make information on food packages more transparent - for example, by providing information on portion sizes in non-numerical ways 
such as "the size of your child's fist" or explicitly stating that one bottle of this drink contains all the sugar a child should consume in a day. Such tools and information on food packages could support parents with lower numeracy, in particular, to determine appropriate portion sizes and to handle other quantitative information when making everyday weight-related decisions.

\section{Conclusion}

This study is the first to identify lower parental numeracy as a predictor of children being under- and overweight. Importantly, parental numeracy was a more important predictor than were specific weight-related numerical information processing skills, such as food label comprehension and portion size estimation. Our findings highlight the role of parental numeracy for interventions targeting childhood obesity and malnutrition. 


\section{References}

Alexy, U., Clausen, K., \& Kersting, M. (2008). Die Ernährung gesunder Kinder und Jugendlicher nach dem Konzept der Optimierten Mischkost [The diet of healthy children and adolescents based on the concept of the optimized mixed diet]. Ernährungsumschau, 3, 168-177.

The German Working Group of Obesity in Childhood and Adolescence, AGA. (2011). Leitlinien für Diagnostik, Therapie und Prävention der Adipositas im Kindes- und Jugendalter [Guidelines for diagnostic, treatment and prevention of obesity in children and adolescents]. Retrieved from http://www.aga.adipositas-gesellschaft.de ARD-Werbegesellschaften. (2014). Media Perspektiven Basisdaten: Daten zur Mediensituation in Deutschland [Media perspectives basic data: Data on the media situation in Germany]. Frankfurt am Main, Germany: Arbeitsgemeinschaft der ARDWerbegesellschaften.

Baranowski, T., Cullen, K. W., Nicklas, T., Thompson, D., \& Baranowski, T. (2003). Are current health behavioral change models helpful in guiding prevention of weight gain efforts? Obesity, 11, 23S-43S. doi:10.1038/oby.2003.222

Ben-Joseph, E. P., Dowshen, S. A., \& Izenberg, N. (2009). Do parents understand growth charts? A national, Internet-based survey. Pediatrics, 124, 1100-1109. doi:10.1542/peds.2008-0797

Chandra, R. K. (2002). Nutrition and the immune system from birth to old age. European Journal of Clinical Nutrition, 56 (Suppl 3), S73-S76. doi:10.1038/sj.ejcn.1601492

Cohen, D. A., \& Babey, S. H. (2012). Contextual influences on eating behaviours: Heuristic processing and dietary choices. Obesity Reviews, 13, 766-779. doi:10.1111/j.1467789X.2012.01001.X

Daniels, S. R. (2009). Complications of obesity in children and adolescents. International Journal of Obesity, 33, S60-S65. doi:10.1038/ijo.2009.20 
Galesic, M., \& Garcia-Retamero, R. (2010). Statistical numeracy for health: A cross-cultural comparison with probabilistic national samples. Archives of Internal Medicine, 170, 462-468. doi:10.1001/archinternmed.2009.481.

Gigerenzer, G., Gaissmaier, W., Kurz-Milcke, E., Schwartz, L. M., \& Woloshin, S. (2007). Helping doctors and patients make sense of health statistics. Psychological Science in the Public Interest, 8, 53-96. doi:10.1111/j.1539-6053.2008.00033.x

Golan, M., \& Crow, S. (2004). Parents are key players in the prevention and treatment of weight-related problems. Nutrition Reviews, 62, 39-50. doi:10.1301/Nr.2004.Jan.3950

Guo, S. S., \& Chumlea, W. C. (1999). Tracking of body mass index in children in relation to overweight in adulthood. American Journal of Clinical Nutrition, 70(1), 145s-148s.

Hu, L. T., \& Bentler, P. M. (1999). Cutoff criteria for fit indexes in covariance structure analysis: Conventional criteria versus new alternatives. Structural Equation Modeling: A Multidisciplinary Journal, 6, 1-55. doi:10.1080/10705519909540118

Hayes, A. F. (2012). PROCESS: A versatile computational tool for observed variable mediation, moderation, and conditional process modeling [Unpublished white paper]. Retrieved from http://www.afhayes.com/ public/process2012.pdf

Huizinga, M. M., Beech, B. M., Cavanaugh, K. L., Elasy, T. A., \& Rothman, R. L. (2008). Low numeracy skills are associated with higher BMI. Obesity (Silver Spring), 16, 1966-1968. doi:10.1038/oby.2008.294

Huizinga, M. M., Carlisle, A. J., Cavanaugh, K. L., Davis, D. L., Gregory, R. P., Schlundt, D. G., \& Rothman, R. L. (2009). Literacy, numeracy, and portion-size estimation skills. American Journal of Preventive Medicine, 36, 324-328.

doi:10.1016/j.amepre.2008.11.012 
Huizinga, M. M., Pont, S., Rothman, R. L., Perrin, E., Sanders, L., \& Beech, B. (2008). ABC's and 123's: Parental literacy, numeracy, and childhood obesity. Obesity Management, 4, 98-103. doi:10.1089/obe.2008.0163

Huybrechts, I., Himes, J. H., Ottevaere, C., De Vriendt, T., De Keyzer, W., Cox, B., . . De Henauw, S. (2011). Validity of parent-reported weight and height of preschool children measured at home or estimated without home measurement: A validation study. BMC Pediatrics, 11, 63. doi:10.1186/1471-2431-11-63

Kline, R. B. (2005). Principles and practice of structural equation modeling. New York, NY: The Guilford Press.

Kurth, B. M., \& Schaffrath Rosario, A. (2007). Die Verbreitung von Übergewicht und Adipositas bei Kindern und Jugendlichen in Deutschland. Ergebnisse des bundesweiten Kinder- und Jugendgesundheitssurveys (KiGGS) [The prevalence of overweight and obese children and adolescents living in Germany. Results of the German Health Interview and Examination Survey for Children and Adolescents (KiGGS)]. Bundesgesundheitsblatt Gesundheitsforschung Gesundheitsschutz, 50, 736-743. doi:10.1007/s00103-007-0235-5

Lipkus, I. M., \& Peters, E. (2009). Understanding the role of numeracy in health: Proposed theoretical framework and practical insights. Health Education \& Behavior, 36, 1065-1081. doi:10.1177/1090198109341533

Lipkus, I. M., Samsa, G., \& Rimer, B.K. (2001). General performance on a numeracy scale among highly educated samples. Medical Decision Making, 21, 37-44. doi:10.1177/0272989X0102100105

Liu, J., Raine, A., Venables, P. H., \& Mendick, S. A. (2004). Malnutrition at age 3 years and externalizing behavior problems at ages 8,11, and 17 years. American Journal of Psychiatry, 161, 2005-2013. doi:10.1176/appi.ajp.161.11.2005 
Lokker, N., Sanders, L., Perrin, E. M., Kumar, D., Finkle, J., Franco, V., . . Rothman, R. L. (2009). Parental misinterpretations of over-the-counter pediatric cough and cold medication labels. Pediatrics, 123, 1464-1471. doi:10.1542/peds.2008-0854

Luder, E., \& Alton, I. (2005). The underweight adolescent. In J. Stang \& M. Story (Eds.), Guidelines for Adolescent Nutrition Services (pp. 93-100). Minneapolis, MN: Center for Leadership, Education and Training in Maternal and Child Nutrition, Division of Epidemiology and Community Health, School of Public Health, University of Minnesota.

Mensink, G. B., Schienkiewitz, A., Haftenberger, M., Lampert, T., Ziese, T., \& Scheidt-Nave, C. (2013). Übergewicht und Adipositas in Deutschland. Ergebnisse der Studie zur Gesundheit Erwachsener in Deutschland (DEGS1) [Overweight and obesity in Germany: Results of the German Health Interview and Examination Survey for Adults (DEGS1)]. Bundesgesundheitsblatt Gesundheitsforschung Gesundheitsschutz, 56, 786-794. doi:10.1007/s00103-012-1656-3

Neuhauser, H., Schienkiewitz, A., Schaffrath Rosario, A., Dortschy, R., \& Kurth, B. M. (2013). Referenzperzentile für anthropometrische Maßzahlen und Blutdruck aus der Studie zur Gesundheit von Kindern und Jugendlichen in Deutschland (KiGGS) [Reference percentiles for anthropometric measures and blood pressure from the Health Interview and Examination Survey for Children and Adolescents in Germany (KiGGS)]. In: Robert-Koch-Institut (Ed). Beiträge zur Gesundheitsberichterstattung des Bundes. Berlin, Germany: Springer.

Nyholm, M., Gullberg, B., Merlo, J., Lundqvist-Persson, C., Rastam, L., \& Lindblad, U. (2007). The validity of obesity based on self-reported weight and height: Implications for population studies. Obesity, 15, 197-208. doi:10.1038/oby.2007.536

OECD. (2013). OECD skills outlook 2013: First results from the Survey of Adult Skills. Paris, France: OECD Publishing. 
Peters, E. (2012). Beyond comprehension: the role of numeracy in judgments and decisions. Current Directions in Psychological Science, 21, 31-35. doi:10.1177/0963721411429960

Peters, E., Hibbard, J., Slovic, P., \& Dieckmann, N. (2007). Numeracy skill and the communication, comprehension, and use of risk-benefit information. Health Affairs, 26, 741-748. doi:10.1377/hlthaff.26.3.741

Peters, E., Meilleur, L., \& Tompkins, M. K. (2013). Numeracy and the affordable care act: Opportunities and challenges. Washington, DC: Institute of Medicine.

Pourshahidi, L. K., Kerr, M. A., McCaffrey, T. A., \& Livingstone, M. B. (2014). Influencing and modifying children's energy intake: The role of portion size and energy density. Proceedings of the Nutrition Society, 73, 397-406. doi:10.1017/S0029665114000615

Pulgaron, E. R., Sanders, L. M., Patino-Fernandez, A. M., Wile, D., Sanchez, J., Rothman, R. L., \& Delamater, A. M. (2014). Glycemic control in young children with diabetes: The role of parental health literacy. Patient Education and Counseling, 94, 67-70. doi:10.1016/j.pec.2013.09.002

Rosas-Salazar, C., Ramratnam, S. K., Brehm, J. M., Han, Y. Y., Acosta-Perez, E., Alvarez, M., ... Celedon, J. C. (2013). Parental numeracy and asthma exacerbations in Puerto Rican children. Chest, 144, 92-98. doi:10.1378/chest.12-2693

Rosseel, Y. (2012). Lavaan: An R package for structural equation modeling. Journal of Statistical Software, 48(2), 1-36. doi:10.18637/jss.v048.i02

Rothman, R. L., Housam, R., Weiss, H., Davis, D., Gregory, R., Gebretsadik, T., . . Elasy, T. A. (2006). Patient understanding of food labels: The role of literacy and numeracy. American Journal of Preventive Medicine, 31, 391-398. doi:10.1016/j.amepre.2006.07.025

Sheridan, S. L., Pignone, M. P., \& Lewis, C. L. (2003). A randomized comparison of patients' understanding of number needed to treat and other common risk reduction formats. 
Journal of General Internal Medicine, 18, 884-892. doi:10.1046/j.1525-

1497.2003.21102.x

Temple, N. J., \& Fraser, J. (2014). Food labels: A critical assessment. Nutrition, 30, 257-260. doi:10.1016/j.nut.2013.06.012

Tulchinsky, T. H. (2010). Micronutrient deficiency conditions: Global health issues. Public Health Reviews, 32, 243-255.

Wang, Y., \& Chen, H.-J. (2012). Use of percentiles and z-scores in anthropometry. In V. R. Preedy (Ed.). Handbook of anthropometry: Physical measures of human form in health and disease (pp. 29-48). London, United Kingdom: Springer. doi:10.1007/9781-4419-1788-1_2

Wansink, B. (2006). Mindless eating: Why we eat more than we think. New York, NY: Bantam.

Watson, S. E., Hannon, T. S., Eckert, G. J., Pratt, J. H., Rosenman, M., \& Tu, W. Z. (2013). Adult hypertension risk is more than quadrupled in obese children. Hypertension, 62, A36

Weiss, R., \& Caprio, S. (2005). The metabolic consequences of childhood obesity. Best Practice \& Research Clinical Endocrinology \& Metabolism, 19, 405-419. doi:10.1016/j.beem.2005.04.009

Weller, J. A., Dieckmann, N. F., Tusler, M., Mertz, C. K., Burns, W. J., \& Peters, E. (2012). Development and testing of an abbreviated numeracy scale: A Rasch analysis approach. Journal of Behavioral Decision Making, 26, 198-212. doi:10.1002/bdm.1751

Williams, M. V., Parker, R. M., Baker, D. W., Parikh, N. S., Pitkin, K., Coates, W. C., \& Nurss, J. R. (1995). Inadequate functional health literacy among patients at 2 public hospitals. Journal of the American Medical Association, 274(21), 1677-1682. doi:10.1001/jama.1995.03530210031026 


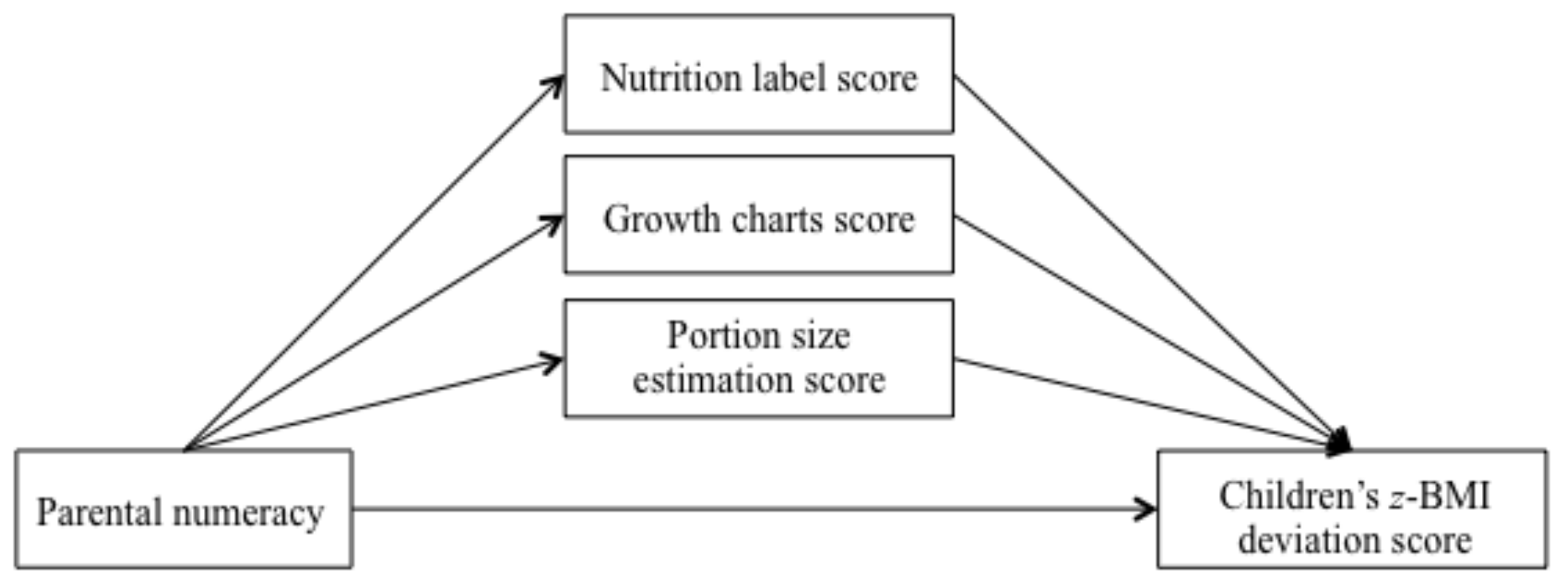


Figure 2 (NO AUTHOR DETAILS)

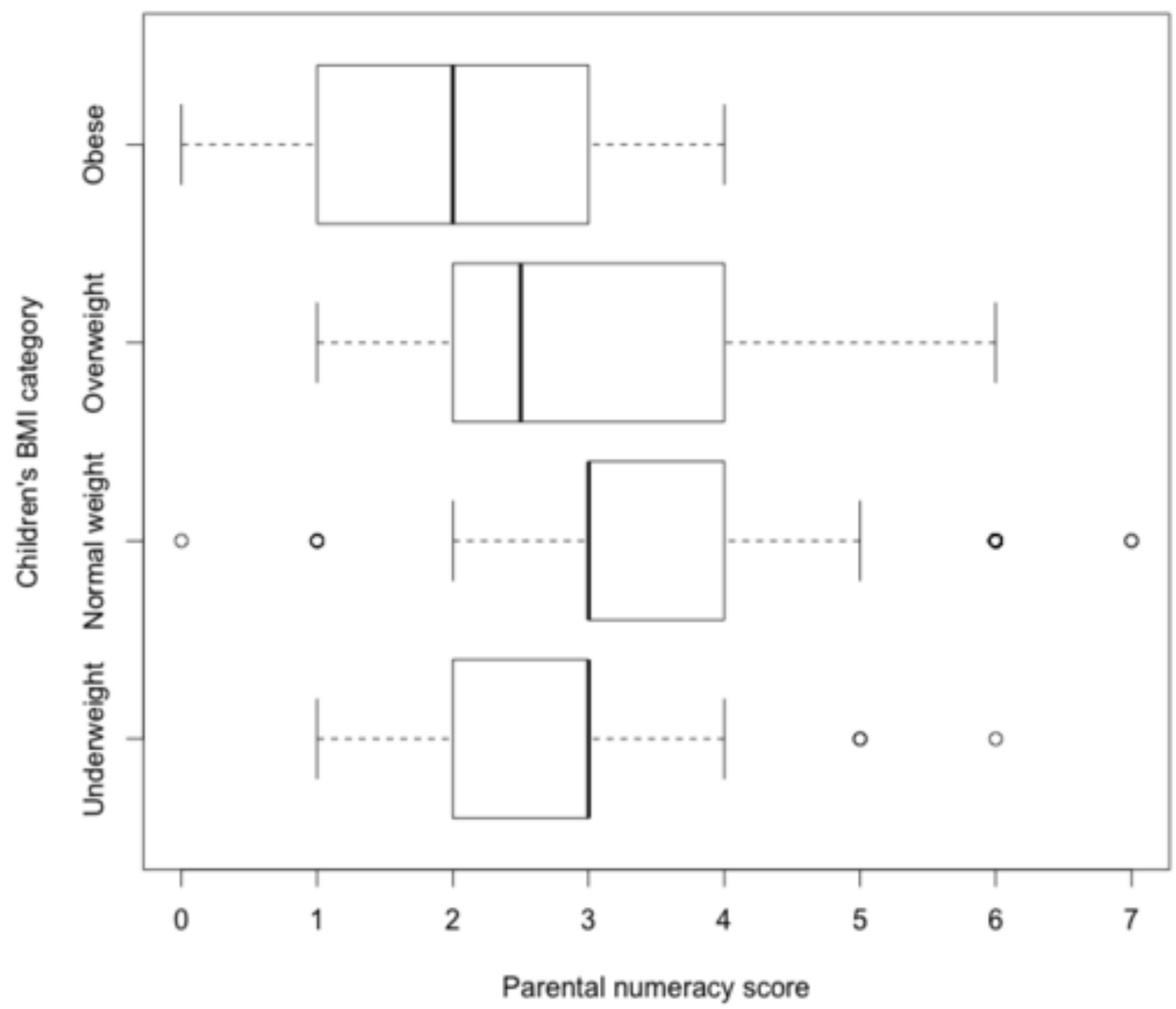




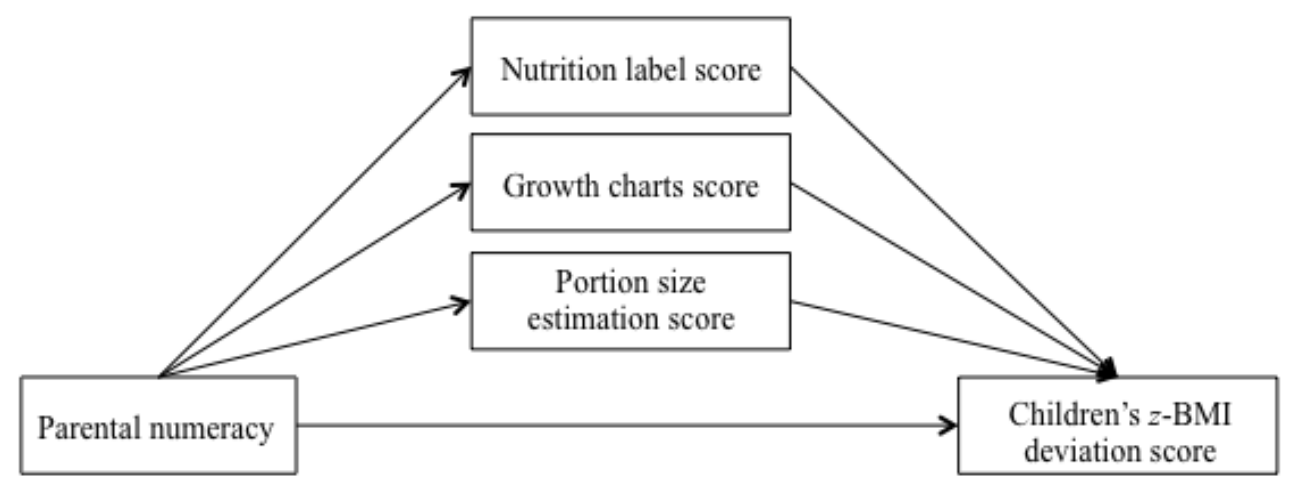

Figure 1. Mediation model of the relationship between parental numeracy and children's $z$-BMI deviation score, as mediated by nutrition label score, growth charts score and portion size estimation. 


\section{Table 1}

Sociodemographic characteristics of the study sample as compared to the German population (in percentages).

\begin{tabular}{|c|c|c|c|c|c|}
\hline & & \multicolumn{2}{|c|}{$\begin{array}{l}\text { Nutritional gatekeeper } \\
\qquad(N=320)\end{array}$} & \multicolumn{2}{|c|}{$\begin{array}{c}\text { Child } \\
(N=320)\end{array}$} \\
\hline & & $\begin{array}{c}\text { Study } \\
\text { sample }\end{array}$ & $\begin{array}{c}\text { German } \\
\text { population }\end{array}$ & $\begin{array}{c}\text { Study } \\
\text { sample }\end{array}$ & $\begin{array}{l}\text { German } \\
\text { population }\end{array}$ \\
\hline \multirow{2}{*}{ Gender } & Male & 14.8 & $15.2^{\mathrm{a}}$ & 45.2 & $51.4^{b}$ \\
\hline & Female & 86.2 & $84.8^{a}$ & 54.8 & $48.6^{b}$ \\
\hline \multirow[t]{11}{*}{ Age } & 6 & & & 16.3 & $13.8^{b}$ \\
\hline & 7 & & & 11.9 & $13.9^{b}$ \\
\hline & 8 & & & 11.3 & $13.8^{b}$ \\
\hline & 9 & & & 17.2 & $14.5^{b}$ \\
\hline & 10 & & & 12.8 & $14.2^{b}$ \\
\hline & 11 & & & 14.1 & $14.5^{b}$ \\
\hline & 12 & & & 16.5 & $15.3^{b}$ \\
\hline & $18-29$ & 8.4 & $6.8^{\mathrm{a}}$ & & \\
\hline & $30-39$ & 44.3 & $41.9^{a}$ & & \\
\hline & $40-49$ & 39.8 & $45.9^{a}$ & & \\
\hline & $50+$ & 7.2 & $5.1^{\mathrm{a}}$ & & \\
\hline \multirow[t]{5}{*}{$\begin{array}{l}\text { Education } \\
\text { levela }\end{array}$} & $\begin{array}{l}\text { Vocational-track } \\
\text { secondary ed. }\end{array}$ & 25.7 & 20.9 & & \\
\hline & $\begin{array}{l}\text { Intermediate-track } \\
\text { secondary ed. }\end{array}$ & 49.9 & 33.5 & & \\
\hline & $\begin{array}{l}\text { Academic-track } \\
\text { secondary ed. }\end{array}$ & 14.7 & 14.6 & & \\
\hline & University degree & 9.4 & 30.7 & & \\
\hline & Not specified & 0.3 & 0.3 & & \\
\hline Size of & 2 & 8.7 & 7.8 & & \\
\hline \multirow[t]{3}{*}{ household ${ }^{a}$} & 3 & 27.4 & 26.1 & & \\
\hline & 4 & 41.1 & 44.7 & & \\
\hline & $5+$ & 22.7 & 21.4 & & \\
\hline
\end{tabular}




\begin{tabular}{|c|c|c|c|c|c|}
\hline & & \multicolumn{2}{|c|}{$\begin{array}{l}\text { Nutritional gatekeeper } \\
\qquad(N=320)\end{array}$} & \multicolumn{2}{|c|}{$\begin{array}{c}\text { Child } \\
(N=320)\end{array}$} \\
\hline & & $\begin{array}{c}\text { Study } \\
\text { sample }\end{array}$ & $\begin{array}{c}\text { German } \\
\text { population }\end{array}$ & $\begin{array}{l}\text { Study } \\
\text { sample }\end{array}$ & $\begin{array}{c}\text { German } \\
\text { population }\end{array}$ \\
\hline Size of place & $<5,0 \overline{00}$ & 22.1 & 15.7 & & \\
\hline \multirow[t]{4}{*}{ of residence ${ }^{a}$} & $5000-19,999$ & 25.9 & 27.5 & & \\
\hline & $20,000-99,999$ & 27.7 & 27.4 & & \\
\hline & $100,000-499,999$ & 10.9 & 14.1 & & \\
\hline & $\geq 500,000$ & 13.4 & 15.3 & & \\
\hline Body Mass & Underweight & & & & \\
\hline \multirow{19}{*}{ Index ${ }^{d}$} & $3-6$ years & & & 9.6 & $5.2^{\mathrm{e}}$ \\
\hline & $7-10$ years & & & 22.4 & $7.8^{\mathrm{e}}$ \\
\hline & $11-13$ years & & & 7.1 & $8.6^{\mathrm{e}}$ \\
\hline & Adults & 2.5 & $2.3^{c}$ & & \\
\hline & Normal weight & & & & \\
\hline & $3-6$ years & & & 65.4 & $85.6^{e}$ \\
\hline & $7-10$ years & & & 61.2 & $76.8^{e}$ \\
\hline & $11-13$ years & & & 79.6 & $72.7^{e}$ \\
\hline & Adults & 49.5 & $51.4^{c}$ & & \\
\hline & Overweight & & & & \\
\hline & $3-6$ years & & & 9.6 & $6.2^{\mathrm{e}}$ \\
\hline & $7-10$ years & & & 6.5 & $9.0^{\mathrm{e}}$ \\
\hline & $11-13$ years & & & 12.2 & $11.4^{\mathrm{e}}$ \\
\hline & Adults & 32.7 & $31.4^{c}$ & & \\
\hline & Obese & & & & \\
\hline & $3-6$ years & & & 15.4 & $2.9 \mathrm{e}$ \\
\hline & $7-10$ years & & & 10.0 & $6.4^{\mathrm{e}}$ \\
\hline & $11-13$ years & & & 1.0 & $7.2^{\mathrm{e}}$ \\
\hline & Adults & 15.3 & $14.9^{c}$ & & \\
\hline
\end{tabular}

aMost comparable representative data for nutritional gatekeepers are for German household managers (defined as "the person in the household responsible for household duties, including food purchases and preparation") from Media Perspective Data, 2014 (ARDWerbegesellschaften, 2014). bRepresentative data for German children from the 2014 microcensus (Kurt \& Schaffrath Rosario, 2007). 
'There are no representative data for the BMI of nutritional gatekeepers; as an approximation, we use representative data for married women in Germany, based on the German Health Update (GEDA) study (Mensink et al., 2013). dUnderweight is defined as a BMI < 18.5 for nutritional gatekeepers and $<10^{\text {th }}$ percentile for children; normal weight as a BMI between 18.5 and 25 for nutritional gatekeepers and between $10^{\text {th }}$ and $90^{\text {th }}$ percentile for children; overweight as BMI $>25$ for nutritional gatekeepers and $>90^{\text {th }}$ percentile for children; obese as BMI $>30$ for nutritional gatekeepers and $>97^{\text {th }}$ percentile for children on the basis of recommended guidelines (AGA, 2011).

eRepresentative data from the KiGGS study (Kurt \& Schaffrath Rosario, 2007) for age groups 3-6 years, 7-10 years, 11-12 years. 
Table 2

Correlations between children's z-BMI, parental education level and numeracy, nutrition label score, growth charts score, and portion size estimation score.

\begin{tabular}{|c|c|c|c|c|c|c|c|c|}
\hline Measures & $\begin{array}{c}1 \\
z-\mathrm{BMI} \\
(N=320) \\
\end{array}$ & $\begin{array}{c}2 \\
\text { Absolute } z \text {-BMI } \\
(N=320)\end{array}$ & $\begin{array}{c}3 \\
z \text {-BMI (normal/over; } \\
n=293)^{\mathrm{a}}\end{array}$ & $\begin{array}{c}4 \\
z \text {-BMI (normal/under; } \\
n=253)^{\mathrm{b}}\end{array}$ & $\begin{array}{c}5 \\
\text { Education } \\
\end{array}$ & $\begin{array}{c}6 \\
\text { Numeracy } \\
\end{array}$ & $\begin{array}{c}7 \\
\text { NL score } \\
\end{array}$ & $\begin{array}{c}8 \\
\text { GC score } \\
\end{array}$ \\
\hline 5. Education & $-.14 *$ & -.06 & -.18 & -.10 & & & & \\
\hline 6. Numeracy & -.10 & $-.38 *$ & $-.32 *$ & $.13^{*}$ & $.13^{*}$ & & & \\
\hline 7. NL score & -.08 & -.04 & -.12 & -.05 & .11 & $.26 *$ & & \\
\hline 8. GC score & -.04 & $-.14^{*}$ & -.13 & .02 & $.14^{*}$ & $.27 *$ & $.34 *$ & \\
\hline 9. PSE score & $-.16^{*}$ & .00 & -.17 & -.11 & .06 & $-.12 *$ & -.09 & -.15 \\
\hline
\end{tabular}

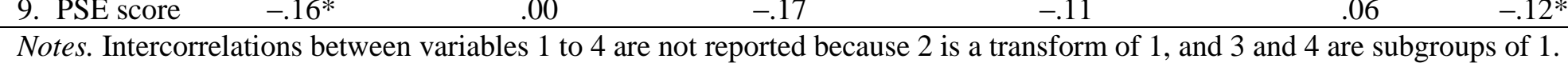

$z$-BMI $=z$-standardized body mass index indicating in what direction (above/positive or below/negative) and by how much a child's BMI deviates from the reference mean; absolute $z$-BMI $=$ absolute deviation from $z$-standardized body mass index indicating how much the child's $z$-BMI deviates from the reference mean without taking into account the direction of the deviation. GC score $=$ comprehension of growth charts. NL score $=$ comprehension of nutrition labels. PSE score $=$ portion size estimation. ${ }^{a}$ Subsample of normal and overweight children. ${ }^{\mathrm{b}}$ Subsample of normal and underweight children. ${ }^{*} p<.05$. 
Table 3

Summary of results from the mediation analysis (5000 bootstrap samples)

\begin{tabular}{|c|c|c|c|c|c|c|c|}
\hline $\begin{array}{l}\text { Independent } \\
\text { variable (IV) }\end{array}$ & Mediating variable (M) & $\begin{array}{c}\text { Dependent } \\
\text { variable } \\
\text { (DV) }\end{array}$ & $\begin{array}{c}\text { Effect of IV } \\
\text { on M (a) }\end{array}$ & $\begin{array}{c}\text { Effect of M } \\
\text { on DV (b) }\end{array}$ & $\begin{array}{c}\text { Direct } \\
\text { effect (c') }\end{array}$ & $\begin{array}{c}\text { Indirect } \\
\text { effect (ab) }\end{array}$ & $\begin{array}{c}\text { Total effect } \\
\text { (c) }\end{array}$ \\
\hline \multirow[t]{4}{*}{ Numeracy } & $\begin{array}{l}\text { Comprehension of } \\
\text { nutrition labels }\end{array}$ & $\begin{array}{l}z \text {-BMI } \\
\text { deviation }\end{array}$ & $0.259 * *$ & -0.041 & $-0.264 * *$ & 0.015 & $-0.257 * *$ \\
\hline & $\begin{array}{l}\text { Comprehension of } \\
\text { growth charts }\end{array}$ & & $0.334 * *$ & -0.035 & & -0.011 & \\
\hline & Portion size estimation & & $-0.077^{*}$ & 0.058 & & 0.003 & \\
\hline & Total & & & & & 0.007 & \\
\hline
\end{tabular}

Note. $N=319 .{ }^{*} p<.05 . * * p<.01$. 